\title{
Possibility of Load Balancing in Middle Voltage Network with the Use of Active Power Filter
}

\author{
Marcin Habrych $^{1}$, Grzegorz Wisniewski ${ }^{1}$, Bogdan Miedzinski ${ }^{2}$, Julian Wosik ${ }^{2}$, Artur Kozlowski ${ }^{2}$ \\ ${ }^{I}$ Department of Electrical Engineering, Wroclaw University of Technology, \\ Wybrzeze Wyspianskiego 27, 50-370 Wroclaw, Poland \\ ${ }^{2}$ Institute of Innovative Technologies, EMAG, \\ Leopolda 31, 40-189 Katowice, Poland \\ marcin.habrych@pwr.edu.pl
}

\begin{abstract}
The paper discusses the impact of unbalanced load on the MV network performance on the example of the power induction furnace for melting metals in the ironwork, demonstrating the ineffectiveness of so far used symmetrization system developed by Steinmetz. Presents the new concept of application of an active power filter (APF) controlled by algorithm based on CPC theory. To confirm the efficiency of such a way of solution the appropriate simulation analyses followed by studies on a physical model of the nonlinear, unbalanced load supplied from MV power network of $6 \mathrm{kV}$ were carried out. On the basis of the investigated results the suitable, practical conclusions have been formulated.
\end{abstract}

Index Terms-Unbalanced load, MV network, active power filter, induction furnace.

\section{INTRODUCTION}

In commonly used MV distribution power networks an unbalance as voltage as currents may be encountered due to asymmetry of both the electric power supply system and the load side. A large share of unbalanced load can cause unbalanced voltage drops in power network and as a result, the asymmetrical voltage values in points of common coupling-switchgear from which are supplied other loads sensitive to voltage asymmetry. For the analysis of such asymmetrical systems the theory of symmetrical components developed in 1918 is commonly used [1]. It is based on the assumption that any unbalanced 3-phase vector system can be decomposed into three symmetrical 3-phase vector systems of particular components: positive, negative and zero-sequence respectively. Thus, calculations of asymmetrical circuits is to solve three symmetrical circuits and application of appropriate superposition. The calculation of particular components of voltage (and currents) can be made according to the following [1]-[3]:

$$
\left[\begin{array}{l}
\underline{U}_{0} \\
\underline{U}_{1} \\
\underline{U}_{2}
\end{array}\right]=\frac{1}{3}\left[\begin{array}{ccc}
1 & 1 & 1 \\
1 & \alpha & \alpha^{2} \\
1 & \alpha^{2} & \alpha
\end{array}\right]\left[\begin{array}{l}
\underline{U}_{L 1} \\
\underline{U}_{L 2} \\
\underline{U}_{L 3}
\end{array}\right],
$$

where $\underline{\mathrm{U}}_{0}, \underline{\mathrm{U}}_{1}, \underline{\mathrm{U}}_{2}$ - complex value of zero-,positive-,and negative components respectively; $\underline{\mathrm{U}}_{\mathrm{L} 1}, \underline{\mathrm{U}}_{\mathrm{L} 2}, \underline{\mathrm{U}}_{\mathrm{L} 3}$ - complex value of phase voltage at particular phase $\mathrm{L}_{1}, \mathrm{~L}_{2}$ and $\mathrm{L}_{3} ; \alpha=$

Manuscript received May 23, 2015; accepted August 14, 2015. $\mathrm{e}^{\mathrm{j} 120}, \alpha^{2}=\mathrm{e}^{\mathrm{j} 240}=\mathrm{e}^{-\mathrm{j} 120}-$ rotation operator.

The current asymmetry (asymmetry of power system as well) is the cause of asymmetrical voltage drops and as a result the asymmetrical supply voltage system $[1\rfloor-\lfloor 3]$ :

$$
\left[\begin{array}{l}
\Delta \underline{U}_{L 1} \\
\Delta \underline{U}_{L 2} \\
\Delta \underline{U}_{L 3}
\end{array}\right]=\frac{1}{3}\left[\begin{array}{ccc}
\underline{Z}_{L 1} & 0 & 0 \\
0 & \underline{Z}_{L 2} & 0 \\
0 & 0 & \underline{z}_{L 3}
\end{array}\right]\left[\begin{array}{c}
\underline{I}_{L 1} \\
\underline{I}_{L 2} \\
\underline{I}_{L 3}
\end{array}\right]
$$

On the plane of complex variables the directions of rotation of the positive and negative components are opposite (the occurrence of the zero sequence component in the system is only possible under certain conditions). Existence of the negative-sequence component and the associated presence of a rotating magnetic field (of the opposite direction of rotation) is very unfavourable for electric induction motors. This is particularly disadvantageous if, in addition to voltage and/or currents unbalance, occurs also the deformation of their waveforms, such as the high harmonics are also present. Therefore, there is urgent need to reduce the asymmetry in any 3-phase circuit both by changing the balance of the particular phase loading or other currently available technical means. The requirement for reducing the negative component amount is the subject of legal regulations set by the operator of the electrical power system. The sources of unbalanced load can be for example welding machines, induction furnaces, and power system when supply a fast wheel traction of a high power of around a few MVA. In this latter case a secondary winding of the supplying power transformer is connected in a "V" two phase system [4]. The problem of the load balancing has been exemplified by performance of a selected induction furnace for melting metals.

\section{UNBALANCED IMPACT OF AN INDUCTOR FURNACE}

Simplified diagram of electrical power to the furnace is illustrated in Fig. 1. In this arrangement the transformer, at its second side, is loaded with inductor turned on between the two phases. In order to perform the load symmetrization the 3-phase power transformer of Dy-5 winding group was selected. Its secondary winding delivering the energy to connected (in delta) a nonlinear load (inductor) together with L, C elements realizing symmetrization circuit developed by Steinmetz [1], [2]. Thus one of the branches of 
the triangle is loaded by the inductor (one phase transformer of the furnace) whereas, the other two by selected inductance $\mathrm{L}_{1}$ and capacity $\mathrm{C}_{1}$ respectively (Fig. 1).

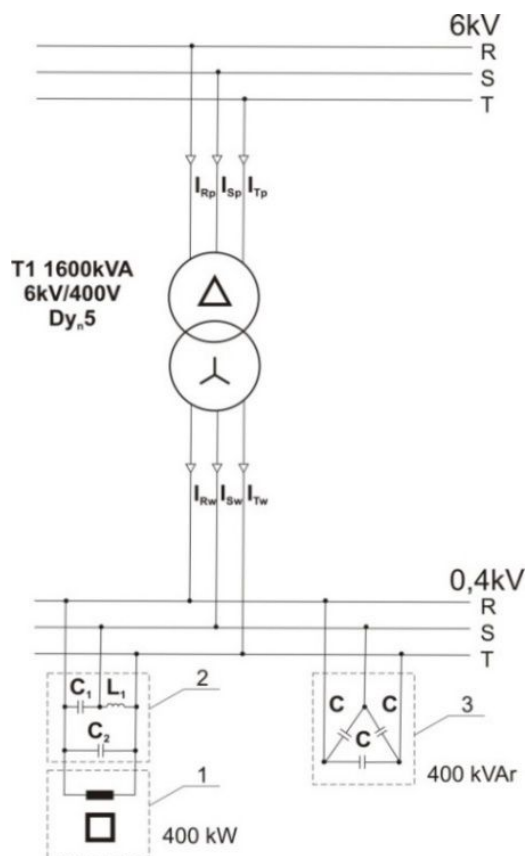

Fig. 1. Simplified electrical connection diagram of the power transformer supplying an induction furnace. 1 - copper melting induction furnace, 2 system of compensation and static load symmetrization ( balancing) of a network, 3 - capacity bank for ph compensation.

The power transformer together with the inductor presents (as seen from the supplying side) the impedance of a relatively small power factor $(\mathrm{pf})$ value $(\cos \varphi \approx 0.34-0.4)$. Hence, to improve the pf and to reduce a loading level of the transformer the additional compensation unit for reactive (inductive) current component of the inductor was used (parallel $\mathrm{C}_{2}$ (Fig. 1)). It is however obvious that for fixed parameters of both capacity and inductance an effective compensation and symmetrization can be obtained only for steady working conditions of the furnace. But under real conditions (in the system) one has to deal practically with the permanent unstable state due to change in the quantity and physical conditions (melting) of metallic charge. Studies have shown that the phase voltage waveforms on the primary side of the transformer are practically sinusoidal however, at large deformations of the currents as presented for example in Fig. 2 and Fig. 3.

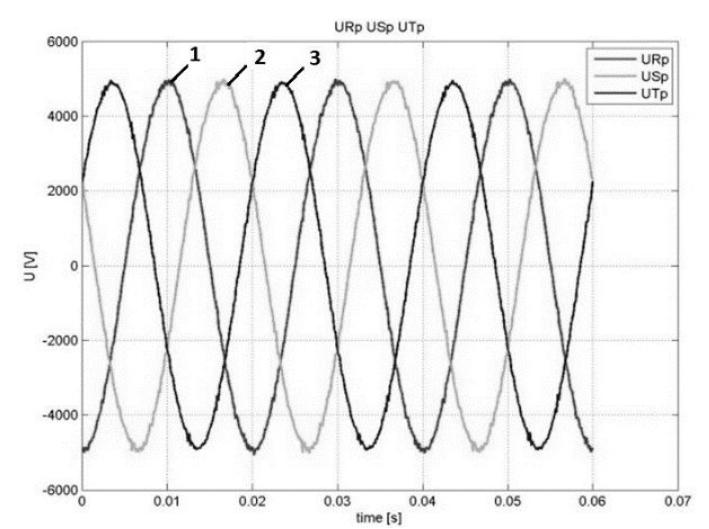

Fig. 2. Instantaneous primary voltages (at $6 \mathrm{kV})$ of the transformer $(1-$ $\left.\mathrm{U}_{\mathrm{Rp}}, 2-\mathrm{U}_{\mathrm{Sp}}, 3-\mathrm{U}_{\mathrm{Tp}}\right)$.

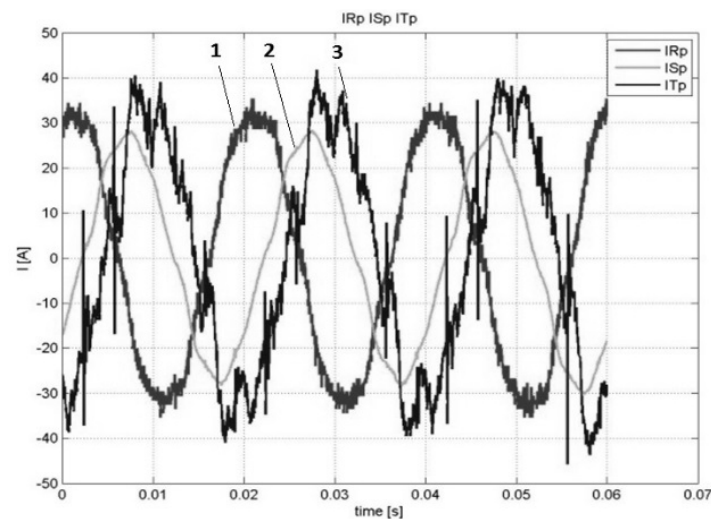

Fig. 3. Instantaneous primary currents of the transformer $\left(1-\mathrm{I}_{\mathrm{Rp}}, 2-\mathrm{I}_{\mathrm{Sp}}, 3\right.$ $\left.-\mathrm{I}_{\mathrm{Tp}}\right)$.

As you can see the phase currents are unbalanced and the maximum difference in their values reach $30 \%$. The situation looks similar on the secondary side of the transformer, but with different deformation of the current waveforms and different their phase shifts (Fig. 4 and Fig. 5). The most distorted is the current in $T$ phase and its instantaneous value is greater than the other currents of about $250 \%$. All this confirms the fact that the symmetrization system applied does not comply with its duties as expected. This was also validated by testing results of the operation of the arrangement for much longer time. Asymmetry of voltages (rms value) as the primary side (about $0.7 \%$ ) and secondary (around $1.5 \%$ ) is almost negligible (Fig. 6 and Fig. 7).

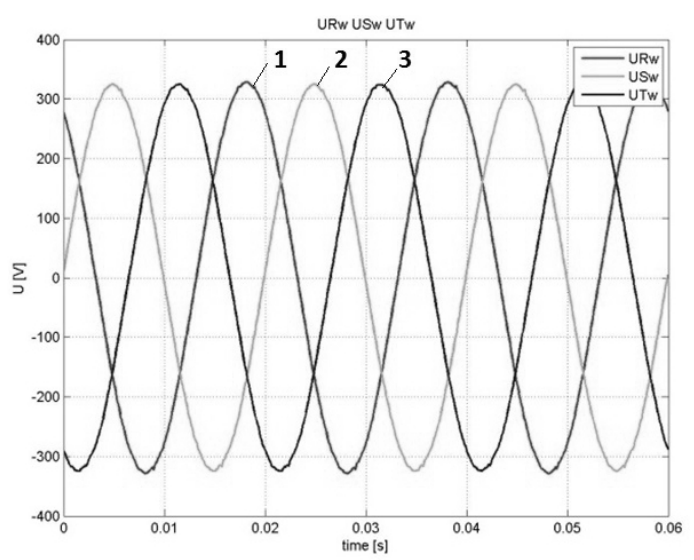

Fig. 4. Instantaneous secondary voltages (at $0.4 \mathrm{kV})$ of the transformer $(1-$ $\left.\mathrm{U}_{\mathrm{Rw}}, 2-\mathrm{U}_{\mathrm{Sw}}, 3-\mathrm{U}_{\mathrm{Tw}}\right)$.

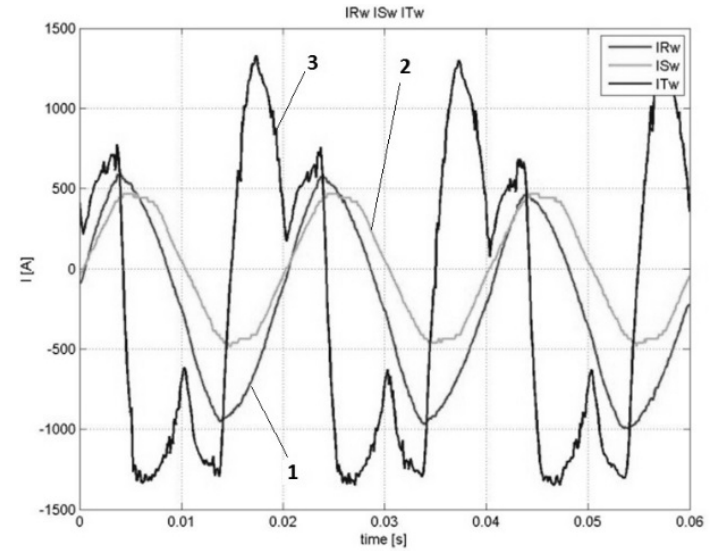

Fig. 5. Instantaneous secondary currents of the transformer $\left(1-I_{R w}, 2-\right.$ $\left.\mathrm{I}_{\mathrm{Sw}}, 3-\mathrm{I}_{\mathrm{Tw}}\right)$ 

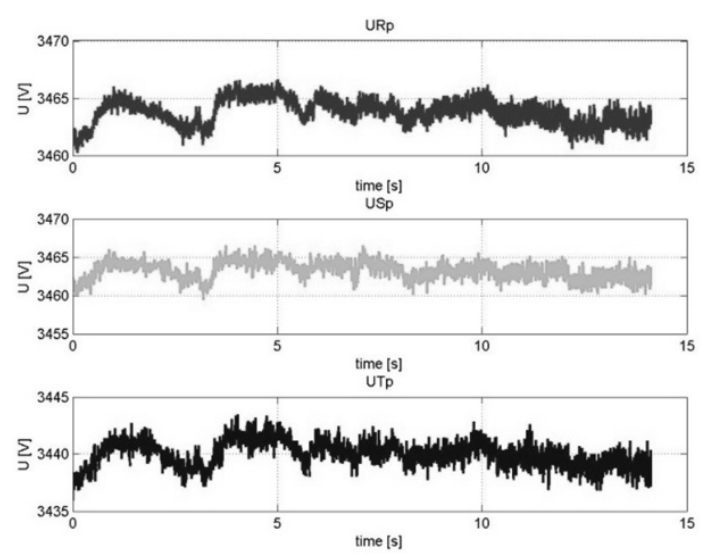

Fig. 6. Variation of rms value of primary voltages (at $6 \mathrm{kV}$ ) of transformer with time.
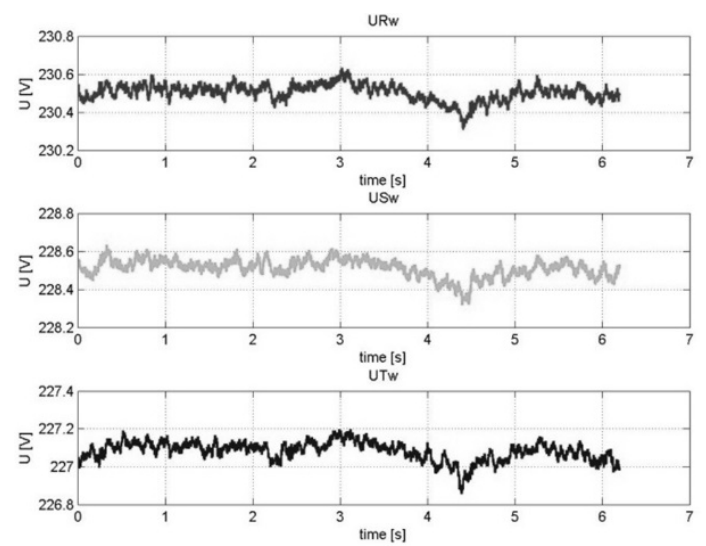

Fig. 7. Variation of rms value of secondary voltages (at $0.4 \mathrm{kV}$ ) of transformer with time.

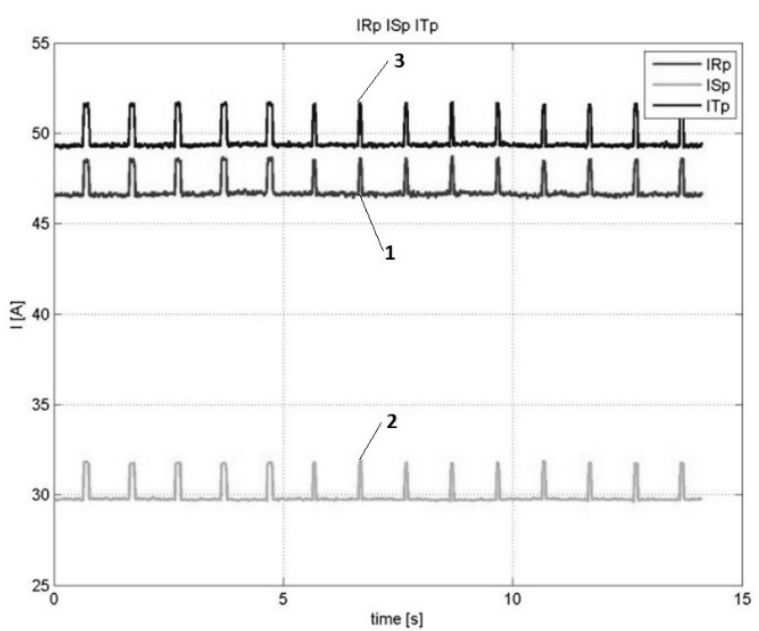

Fig. 8. Variation of rms value of primary currents with time $\left(1-\mathrm{I}_{\mathrm{Rp}}, 2-\right.$ $\left.\mathrm{I}_{\mathrm{Sp}}, 3-\mathrm{I}_{\mathrm{Tp}}\right)$.

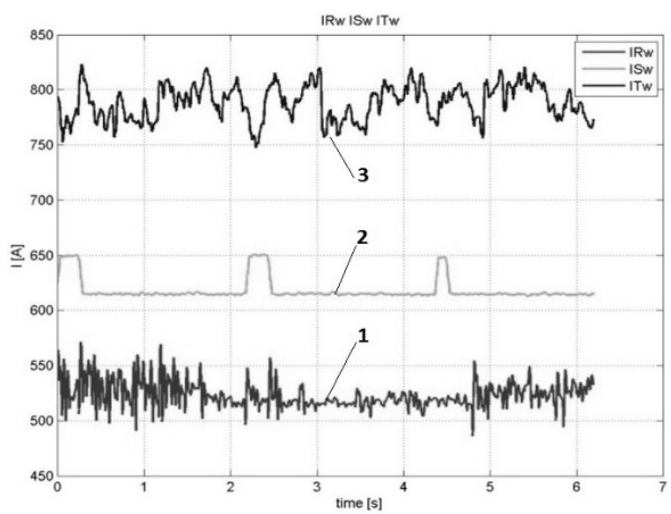

Fig. 9. Variation of rms value of secondary currents with time $\left(1-\mathrm{I}_{\mathrm{Rw}}, 2-\right.$ $\left.\mathrm{I}_{\mathrm{Sw}}, 3-\mathrm{I}_{\mathrm{Tw}}\right)$.
Completely different maters however, is with currents. A significant and comparable current asymmetry is visible on both sides of the transformer (Fig. 8 and Fig. 9). This state of the power supply load is undesirable and should therefore be taken measures to improve the load symmetrisation.

\section{APPLICATION OF ACTIVE POWER FILTER}

Balancing possibility of both linear and/or non-linear asymmetric loads is currently associated with active power filters (APF) [4]-[6]. These filters have been developed for the purpose of reactive power compensation and elimination of current harmonics in circuit with non-sinusoidal current and voltage waveforms. Contemporary theories of power however, provide a basis for the development of the balancing systems for unbalanced and nonlinear loads.

Particularly useful is the theory of the physical current components. It specifies the complex power $S_{h}$ for h-order of high harmonics as a scalar product

$$
\underline{S}_{h}=\underline{U}_{h}^{T} \times \underline{I}_{h}^{*}=P_{h}+j Q_{h},
$$

where $P_{h}, Q_{h}$ - active and reactive power (for h-harmonics), $\underline{U}_{h}{ }^{T}$ - complex voltage as a matrix (for h-harmonics), $\underline{I}_{h}{ }^{*}$ complex conjugate current (for h-harmonics).

For passive, linear load an active power transferred from source to load is positive for each harmonics i.e. $\mathrm{P}_{\mathrm{h}} \geq 0$. However, if the load is nonlinear and/or not passive respective harmonics are generated ad active power due to them flows towards the source. Therefore, resultant set of all harmonics can be divided into respective subsets $\mathrm{N}_{\mathrm{A}}$ and $\mathrm{N}_{\mathrm{B}}$ :

$$
\left\{\begin{array}{l}
\text { if } P_{h} \geq 0 \text { thus } h \in N_{A}, \\
\text { if } P_{h}<0 \text { thus } h \in N_{B} .
\end{array}\right.
$$

As a result both voltage $u$, current $i$ and active power $P$ has been resolved into two following components:

$$
\left\{\begin{array}{l}
i=\sum_{h \in N} i_{h}=\sum_{h \in N_{A}} i_{h}+\sum_{h \in N_{B}} i_{h}=i_{A}+i_{B}, \\
u=\sum_{h \in N} u_{h}=\sum_{h \in N_{A}} u_{h}-\sum_{h \in N_{B}} u_{h}=u_{A}-u_{B}, \\
P=\sum_{h \in N} P_{h}=\sum_{h \in N_{A}} P_{h}-\sum_{h \in N_{B}} P_{h}=P_{A}-P_{B} .
\end{array}\right.
$$

Hence, the energy source and receiver are alternately source and/or load. Thus, one has to consider two equivalent circuits as shown in Fig. 10 and Fig. 11.

The CPC theory distinguishes 5 physical current components

$$
i=i_{a}+i_{s}+i_{r}+i_{u}+i_{B}
$$

each of which is related to separate energy phenomena [5], [7]-[12] as follows:

- the active component $i_{a}$ responsible for the transmission of active power from source to the receiver (load),

- passive component $i_{\mathrm{r}}$ correlated with the occurrence of the receiver susceptance,

- component $i_{B}$ containing higher harmonics generated to network by a non-linear load, 
- scattered component $i_{s}$ occurring at presence of higher harmonics in the supply voltage (voltage waveform deformation) and if the impedance of the load is dependent on the frequency of the supply voltage,

- unbalance component $i_{u}$ in the absence of balance at sources and/or load sides.



Fig. 10. Electric scheme for consideration according CPC theory; $u_{\mathrm{s}}-$ source voltage, $\mathrm{u}=\mathrm{u}_{\mathrm{A}}-\mathrm{u}_{\mathrm{B}}-$ voltage at load terminal, $\mathrm{i}-$ load current, $\mathrm{z}_{\mathrm{s}}$ source impedance, $\Delta \mathrm{u}_{\mathrm{s}}$ - voltage drop due to $\mathrm{i}_{\mathrm{A}}, \mathrm{u}_{\mathrm{B}}=\Delta \mathrm{u}_{\mathrm{B}}-$ voltage drop due to $\mathrm{i}_{\mathrm{B}}, \mathrm{N}_{\mathrm{A}}$ - harmonics set in $\mathrm{u}_{\mathrm{A}}, \mathrm{N}_{\mathrm{B}}$ - harmonics set in $\mathrm{i}_{\mathrm{B}}$ and $\mathrm{u}_{\mathrm{B}}, \mathrm{N}=\mathrm{N}_{\mathrm{A}}+\mathrm{N}_{\mathrm{B}}$.

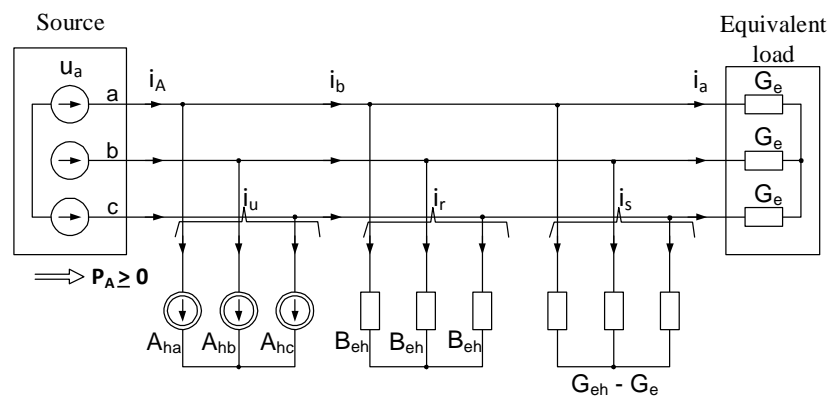

a)

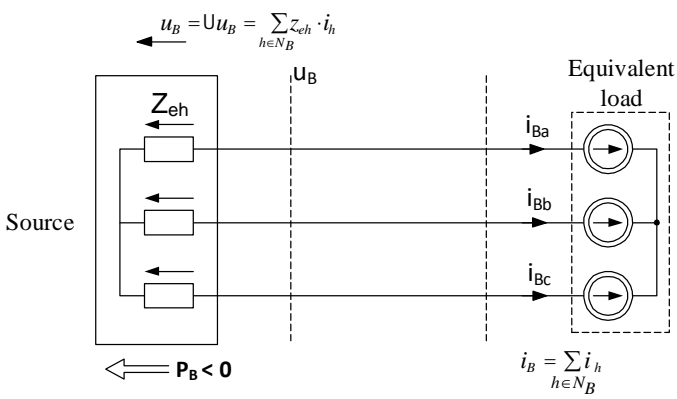

b)

Fig. 11. Equivalent circuit; a) for $h \in N_{A}$, b) for $h \in N_{B}$.

Instantaneous values of currents components can be calculated from the following:

$$
\begin{aligned}
& i_{a}=G_{e} u_{A}, \\
& i_{s}=\sqrt{2} R e \sum_{h \in N_{A}}\left(G_{e h}-G_{e}\right) \underline{U}_{A h} e^{j h \omega_{1} t}, \\
& i_{r}=\sqrt{2} R e \sum_{h \in N_{A}} j B_{e h} \underline{U}_{A h} e^{j h \omega_{1} t}, \\
& i_{u}=\sum_{h \in N_{A}} i_{u h}=\sqrt{2} R e \sum_{h \in N_{A}} \underline{A}_{h} \underline{U}_{A h} e^{j h \omega_{1} t}, \\
& i_{B=} \sum_{h \in N_{B}} i_{h},
\end{aligned}
$$

where $\mathrm{G}_{\mathrm{e}}$ - phase conductance for equivalent 3-phase symmetrical load, $A_{h}, B_{\text {eh }}, G_{\text {eh }}$ - admittance, susceptance and conductance for particular harmonics $h, \omega_{1}-$ angular frequency for basic harmonics, $\mathrm{t}$ - time.

Their rms values are respectively perpendicular and form a polygon as illustrated in Fig. 12.

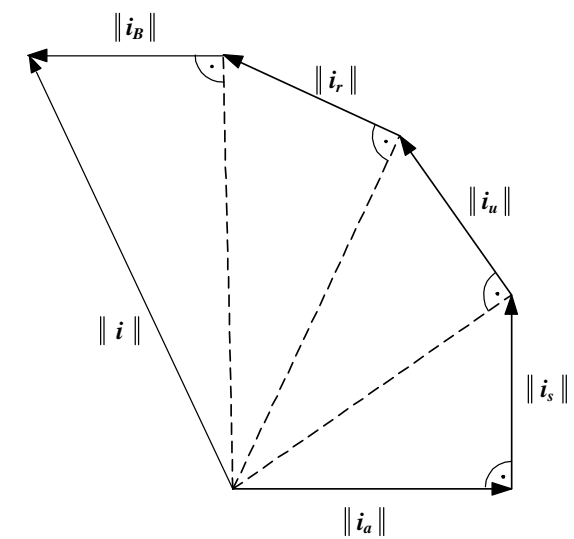

Fig. 12. Polygon of the current components.

A detailed description of the (CPC) method and way of its implementation is given, inter alia, in [3], [10].

Developed, based on the above theory, the active filter control algorithm (Fig. 13) enables efficient balancing of load currents thus achieve the effect that is great of interest both for the power system operator and consumers.

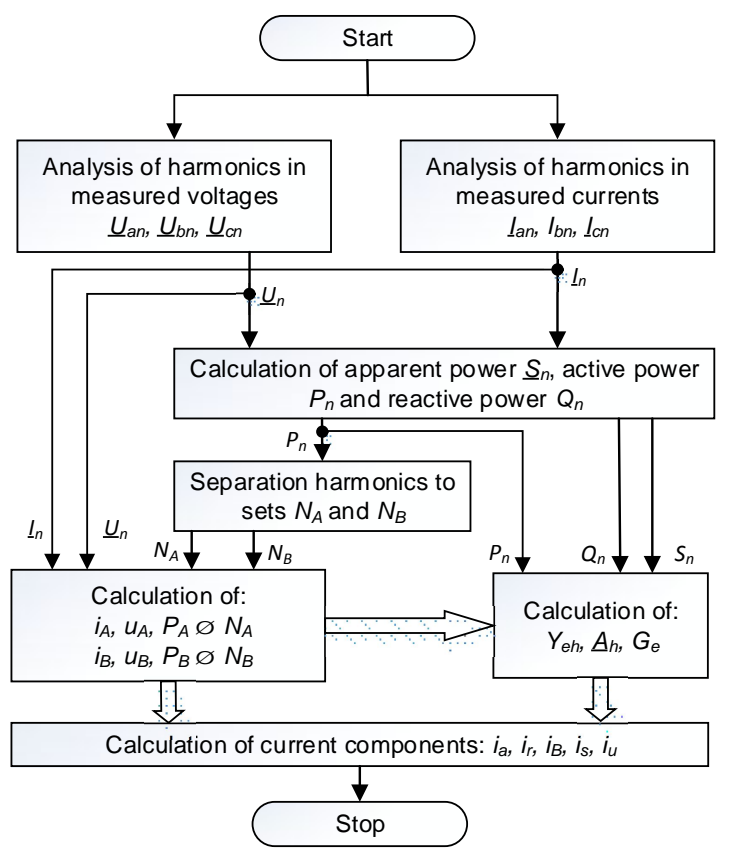

Fig. 13. Algorithm of control Active Power Filter basing on current physical components theory (CPC).

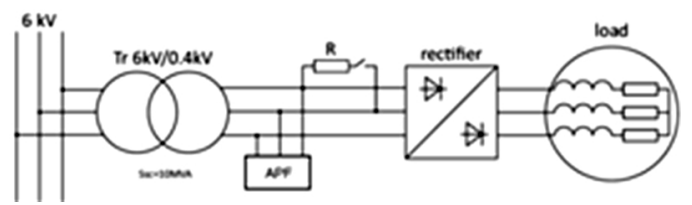

Fig. 14. Simplified scheme of arrangement for testing balancing efficiency using active power filter (APF), R-resistance for modelling the load unbalance.

Authors therefore have undertaken the appropriate simulation study and following experimental investigations for both linear symmetrical and non-linear non-symmetrical loads respectively. As a non-linear receiver were used a 3phase controlled rectifier loaded with RL impedance. 
Whereas, the asymmetry extorted by connection of an appropriately selected resistance $\mathrm{R}$ value between the two phases of the low voltage power supply circuit as shown in Fig. 14.

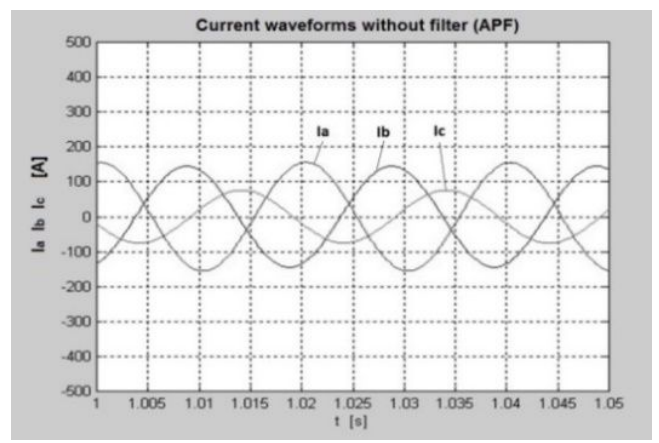

a)

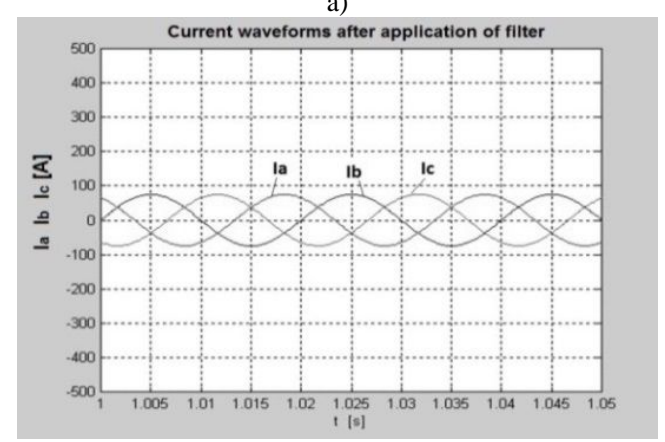

b)

Fig. 15. Effect of APF application on load balancing for linear nonsymmetrical load; a - current waveforms without filter (APF), b - current waveforms after application of filter.

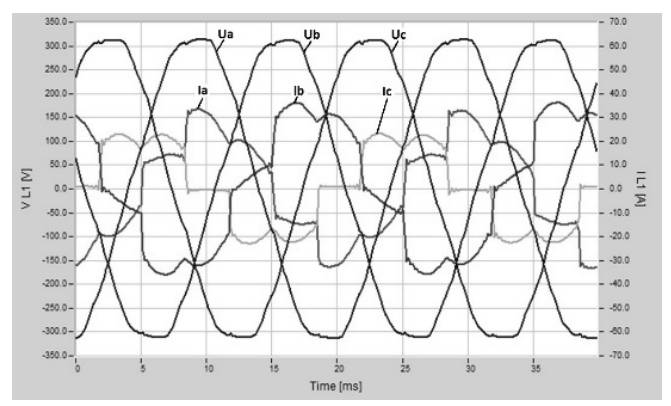

a)

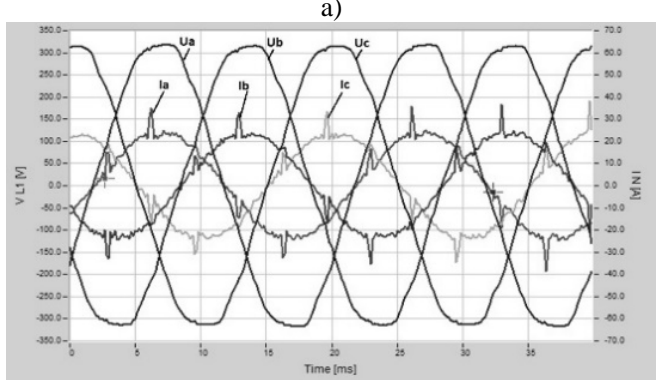

b)

Fig. 16. Effect of APF application on load balancing for non-linear, nonsymmetrical load; a - voltage and current waveforms before APF use, b when use APF.
The study showed that after application of the developed active power filter the load balance was effectively achieved in all the cases studied. Selected, for example results of investigations are shown in Fig. 15 and Fig. 16 respectively.

\section{CONCLUSIONS}

Unbalanced load is often found in municipal and industrial networks and is largely responsible for the deterioration of the quality of electricity. Example of this might be the power supply of induction furnaces for melting metals where the use of traditional static balancing method (developed by Steinmetz) does not give the desired results. Conducted by the authors study in conditions as laboratory and real confirmed the usefulness of developed active power filter (controlled by the algorithm according to the theory of physical current components) for effective balancing of 3phase electrical circuits with linear as well as non-linear loads. It is planned to develop the structure of this type of balancing system for use in metal foundries.

\section{REFERENCES}

[1] C. L. Forescue, "Method of symmetrical coordinates applied to the solution of polyphase network", Trans. AIEE, vol. 37, 1917.

[2] Ch. P. Steinmetz, Lectures on Electrical Engineering. New York: Dover, 1897.

[3] L. S. Czarnecki, "Powers of asymetrical loads in therms of the CPC theory", Electrical Power Quality and Utilisation Journal, vol. 13, no. 1, pp. 97-103, 2007.

[4] C. Ladniak, J. Rull, "Symetrization of loads in power system suppling high speed faliwey", Traction.Logistic, no. 6, pp. 2321-2325, 2012.

[5] J. Wosik, M. Kalus, A. Kozlowski, B. Miedzinski, M. Habrych, "The efficiency of reactive power compensation of high power nonlinear loads", Elektronika ir Elektrotechnika, vol. 19, no. 7, pp. 29-32, 2013. [Online]. Available: http://dx.doi.org/10.5755/j01.eee.19.7.5158

[6] R. Hou, J. W. Y. Liu, D. Xu, "Generalized design of shunt active power filter with output LCL filter", Elektronika ir Elektrotechnika, vol. 20, no. 5, pp. 65-71, 2014. [Online]. Available: http://dx.doi.org/10.5755/j01.eee.20.5.3910

[7] X. Liu, J. Wang, G. Yao, "A novel hysteresis current control strategy with fuzzy bandwidth for active power filter", Elektronika ir Elektrotechnika, vol. 120, no. 4, pp. 3-8, 2012. [Online]. Available: http://dx.doi.org/10.5755/j01.eee.120.4.1442

[8] T. Dong, L. Li, Z. Ma, "A combined system of APF and SVC for power quality improvement in microgrid", IEEE Power Engineering and Automation Conf. (PEAM 2012), 2012, pp. 1-4. [Online]. Available: http://dx.doi.org/10.1109/peam.2012.6612554

[9] N. Pawar, R. D. Patidar, L. C. Patidar, "An optimal controller for APF for customer harmonics and reactive power compensation", Engineering and Systems (SCES), pp. 1-6, 2012.

[10] L. S. Czarnecki, "Minimization of unbalanced and reactive currents in three-phase asymmetrical circuit with non sinusoidal voltage", in IEE Proc. B Electric Power Applications, pp. 347-354, 1992.

[11] Z. X. Zou, K. Zhou, Z. Wang, et al., "Frequency-adaptive fractionalorder repetitive control of shunt active power filters", IEEE Trans. Industrial Electronics, vol. 62, no. 3, pp. 1659-1668, 2015. [Online] Available: http://dx.doi.org/10.1109/TIE.2014.2363442

[12] P. Kanjiya, V. Khadkikar, H. H. Zeineldin, "Optimal control of shunt active power filter to meet IEEE Std. 519 current harmonic constraints under nonideal supply condition", IEEE Trans. Industrial Electronics, vol. 62, no. 2, pp. 724-734, 2015. [Online]. Available: http://dx.doi.org/10.1109/TIE.2014.2341559 